\title{
Marital Relationships in the Twenty-First Century
}

By: $\underline{\text { Heather M. Helms }}$

Helms, H. M. (2013). Marital relationships in the 21st century. In G. W. Peterson and K. R. Bush (Eds.) Handbook of Marriage and Family, Third Edition. (pp. 233 - 254). New York: Springer Publishing Company.

Made available courtesy of Springer: https://doi.org/10.1007/978-1-4614-3987-5

****(C) 2013 Springer Science+Business Media New York. Reprinted with permission. No further reproduction is authorized without written permission from Springer. This version of the document is not the version of record. Figures and/or pictures may be missing from this format of the document. ***

\section{Abstract:}

Nearly 50 years ago, when the first edition of the Handbook of Marriage and Family was published, family scholars underscored the central importance of marriage in individuals' lives and accordingly advocated for a better understanding of those factors that predict marital success and positive marital adjustment (Bernard, 1964; Bowerman, 1964). It is unclear whether these pioneering family scholars recognized as early as 1964 that they were on the precipice of significant social changes that would define the latter half of the twentieth century as a period of marital "deinstitutionalization" (Cherlin, 2004) or the "world-historic transformation" of marriage (Coontz, 2004). Prior to the Handbook's second edition in 1987, however, they certainly knew something was up (see Bernard's The Future of Marriage, 1972). Evidenced by marriage rate declines, increases in nonmarital cohabitation and childbearing, the postponement of marriage, and elevated divorce rates, marriage has become one of several legitimate options for organizing couple relationships and reproduction in the United States and other Western countries (Amato, 2004; Fincham \& Beach, 2010). Whether or not these trends signify declines in the value of marriage or simply reflect societal change has been hotly debated. Religious leaders, politicians, clinicians, and the federal government have all weighed in on the debate and have allocated significant resources to promote marriage as the ideal. Although skepticism remains about the utility of these steps (Huston \& Melz, 2004; Karney \& Bradbury, 2005), most scholars agree that the current coexistence of marriage with multiple forms of other relationship and childrearing options is unprecedented.

Keywords: marital research | marital behavior $\mid$ macroenvironment | individuals | marriage

\section{Chapter:}

Nearly 50 years ago, when the first edition of the Handbook of Marriage and Family was published, family scholars underscored the central importance of marriage in individuals' lives and accordingly advocated for a better understanding of those factors that predict marital success and positive marital adjustment (Bernard, 1964; Bowerman, 1964). It is unclear whether these pioneering family scholars recognized as early as 1964 that they were on the precipice of 
significant social changes that would define the latter half of the twentieth century as a period of marital "deinstitutionalization" (Cherlin, 2004) or the "world-historic transformation" of marriage (Coontz, 2004). Prior to the Handbook's second edition in 1987, however, they certainly knew something was up (see Bernard's The Future of Marriage, 1972). Evidenced by marriage rate declines, increases in nonmarital cohabitation and childbearing, the postponement of marriage, and elevated divorce rates, marriage has become one of several legitimate options for organizing couple relationships and reproduction in the United States and other Western countries (Amato, 2004; Fincham \& Beach, 2010). Whether or not these trends signify declines in the value of marriage or simply reflect societal change has been hotly debated. Religious leaders, politicians, clinicians, and the federal government have all weighed in on the debate and have allocated significant resources to promote marriage as the ideal. Although skepticism remains about the utility of these steps (Huston \& Melz, 2004; Karney \& Bradbury, 2005), most scholars agree that the current coexistence of marriage with multiple forms of other relationship and childrearing options is unprecedented.

What has remained constant across these decades characterized by demographic flux is an unwavering endorsement of marriage as a desired goal (Axinn \& Thornton, 2000), even among those individuals who may be least likely to marry (England \& Edin, 2007) or are excluded from marriage (Walker, 2004). (Ironically, some have argued that it may be the very nature of contemporary expectations for marriage that have contributed to its fragility.) At the same time, scholarly attention to marriage not only remains strong but has nearly doubled in the past decade making a comprehensive review of this burgeoning literature virtually impossible within any single manuscript or book chapter. Clearly, marriage has been and continues to: (a) maintain symbolic importance for individuals living within and outside it, (b) be an important focus of scientific inquiry, and (c) generate significant public interest and debate. Simply put, at the beginning of the twenty-first century, marriage continues to matter.

While scholars have acknowledged the complexity of marital relationships for decades, situating marriage in the context of other relationships and environments and systematically studying the links between them is a relatively new contribution from research conducted in the new millennium (Fincham \& Beach, 2010). Made possible by methodological and analytic advances (see Chap. 3) and deemed essential for understanding the marital experiences beyond the White and middle class (Bradbury \& Karney, 2004; Helms, Supple, \& Proulx, 2011; Huston \& Melz, 2004; McAdoo, Martinez, \& Hughes, 2005), contemporary scholars are increasingly situating their understanding of marriage in context. Various theoretical perspectives have informed this expanse in focus including the Family Stress Model (Conger et al., 1990), the Vulnerability-Stress-Adaptation Model (VSA, Karney \& Bradbury, 1995), Peters and Massey's (1983) Mundane Extreme Environmental Stress Model (MMES, Murry, Brown, Brody, Cutrona, \& Simons, 2001), and most recently Huston's (2000) three-level model of marriage. Huston's model is perhaps the most comprehensive of these perspectives in that it integrates principles from several behavioral, social-psychological, and contextual theories that have been applied to marriage to inform an integrated, interdisciplinary theoretical model. Accordingly, Huston's model and more recent adaptations of it for diverse samples (Helms et al., 2011) provide a useful framework for the accumulation of empirical findings on marriage that have emerged in the past decade. 
In this chapter, Huston's (2000) three-level model of marriage is introduced as a heuristic for future research as well as an organizational tool for framing the current review. Huston's model provides a roadmap of sorts for understanding marriage in the twenty-first century in that it does not necessarily depict a new way of viewing marital relationships (see Kelley et al., 1983), but integrates across a variety of theoretical perspectives to provide a more comprehensive model for the study of marriage than has previously been explored. Using Huston's model as a guide, new areas of discovery are highlighted as well as research that characterizes central domains of inquiry that have not been written about extensively in other recent, major reviews. In taking this approach, the goal of this chapter is not to offer a singular empirical model to be tested or an exhaustive review of all research on marriage that has emerged since the 1999 edition of the Handbook of Marriage and Family. Instead, in this chapter, the value of a theoretical approach for highlighting recent and relevant advances in the study of marriage and for informing the types of research questions that should be addressed in future work is demonstrated. In so doing, the chapter lays the groundwork for future research to focus on the multilayered and interdependent contextual factors that characterize, maintain, modify, and interact with the marital experiences of diverse couples in the twenty-first century.

To provide a general overview of marital research conducted since the last publication of the Handbook, the chapter begins with a content analysis of the literature appearing in leading journals across disciplines that regularly publish in this area. Because other chapters in the Handbook focus on the partnerships of cohabiting and lesbian and gay couples (see Chaps. 11 and 26), this chapter is more narrowly focused on the experiences of heterosexual, married couples and reflects the substantive topics most frequently studied (i.e., martial behavior, stability, satisfaction, and other dimensions of marital quality). After presenting findings from the content analysis, Huston's (2000) three-level model of marriage is introduced as a frame for the current literature. In discussing each component of the model (i.e., marital behavior, individuals, and the macroenvironment) and the potential linkages between them, related literature from the past decade is reviewed and directives for future research are presented. Using Huston's model as a guide, the chapter closes with suggestions for future work, including recommendations for testing complex associations between elements of the model with diverse populations.

\section{Scope of Review}

To inform an understanding of marital relationships in the twenty-first century, scholarly work featured in 11 journals representing several fields that have historically published articles on marriage was identified including two interdisciplinary journals. In selecting journals for consideration, several criteria were used including an emphasis on marital research, journal impact (e.g., impact index estimates and/or an association with a professional society with a focus on marital relationships), and citation rates. The 11 journals selected were: The Journal of Marriage and Family, Journal of Family Issues, and Family Relations, representing family studies; the Journal of Family Psychology and Journal of Personality and Social Psychology, representing psychology; American Sociological Review and the American Journal of Sociology, representing sociology; Communication Monographs and Human Communication Research representing interpersonal communication, and the Journal of Social and Personal Relationships and Personal Relationships, which are interdisciplinary journals that publish 
manuscripts on marital relationships from a variety of fields. To identify articles, the title and the abstract of each article published in these journals across the 10-year span of 2000-2009 were reviewed. Articles were included for analysis if they fit criteria for marital research; articles solely focused on dating, mate selection, or cohabitation were excluded unless there was a clear link with some aspect of marital relationships in the abstract. Articles with samples characterized by predominantly married couples or individuals and a smaller proportion of cohabiting partners were included if the substantive focus of the study involved some aspect of marital relationships. Using these criteria, 411 articles were identified, 24 of which were nonempirical. (Reference list is available from the author.)

A content analysis of each article was conducted to further inform the review. Articles were categorized into four primary substantive categories: marital behavior, marital stability, marital satisfaction, and marital quality-other. In cases where article content spanned several categories, articles were coded for each relevant area of substantive focus. Because the marital behavior literature has been recently critiqued as heavily focused on marital conflict rather than more positive or affirming dimensions of behavior (Fincham \& Beach, 2010), additional subcategories were employed to differentiate articles in the marital behavior category that focused on marital conflict, power/decision-making, discord, negativity, and hostility from those focused on marital warmth, support, forgiveness, and positive communication. After coding the substantive focus of each article, empirical articles were further coded based on sample characteristics (i.e., average age of participants, racial composition), research design (i.e., cross-sectional, longitudinal, and short-term longitudinal defined as time-series or daily diary approaches), and whether the sample was comprised of married couples or married individuals. Coding the 387 empirical articles in this manner made the analysis of general patterns across all articles possible as well an analysis of manuscripts by each of the five substantive categories. Results of the content analysis provide both a general overview of the nature of marital research in the first decade of twenty-first century and also make it possible to identify emerging bodies of work as well as unique or cutting-edge research. Therefore, although all of the 411 articles are included in the results reported for the content analysis, not all coded articles are integrated into the literature reviewed which is more narrowly focused on advances in the study of marital relationships and directions for future work.

\section{General Patterns in the Marital Literature}

Overall, the content analysis showed that the bulk of the marital research published in the past decade was quantitative with just over half of the studies employing cross-sectional designs with convenience samples of primarily White couples between the ages of 30 and 40, on average, with a focus on marital behavior. Specifically, 53\% of the articles reviewed focused on some aspect of marital behavior. The remaining literature was relatively evenly divided in its focus on marital stability (14\%), marital satisfaction (19\%), and marital quality-other (14\%). The majority of empirical articles reviewed were quantitative in nature $(96 \%)$. Of the qualitative articles that were published in the past decade, the majority $(71 \%)$ focused on dimensions of marital behavior and included topics such as marital power, decision-making and equality, marital uncertainty, spouses' strategies for resolving intergenerational conflicts, and displays of commitment in marriage. Just over half of all studies reviewed were cross-sectional (54\%). Longitudinal designs represented $41 \%$ of the work conducted in the past decade, and $5 \%$ of the empirical articles 
reviewed employed short-term longitudinal designs utilizing time-series or daily diary approaches. Regarding sampling, just over half (54\%) of the empirical articles were based on studies utilizing predominantly White, convenience samples. Studies utilizing nationally representative samples, diverse convenience samples $(<70 \%$ White), and studies without enough information to determine sample characteristics were relatively equally represented in the empirical literature reviewed (i.e., 10\%, 9\%, and 10\%, respectively). International, non-US samples were utilized in $16 \%$ of the studies reviewed, and $1 \%$ of articles included convenience samples of African Americans. With one exception (see Leidy, Parke, Cladis, Coltrane, \& Duffy, 2009), no within-group studies of marriage for Latino or other immigrant groups were identified across the 10 years of literature reviewed. Sixty-six percent of the empirical articles reviewed included samples of married couples, whereas $34 \%$ consisted of samples of married individuals. A third of the empirical articles focused on the marital relationships of spouses in their 20 s. Just over half $(51 \%)$ of the studies focused on the marital experiences of spouses aged 30-40 years, and less than 1\% addressed the marital experiences of spouses aged 50 and over. The remaining studies (15\%) did not specify the age of their participants.

\section{Marital Behavior}

Results of the content analysis showed that in the past decade, studies of marital behavior were largely published in family studies, psychology, and close relationships journals (99\%). Similar to the general trends identified in the larger marital literature of the past decade, the majority of articles focused on marital behavior were cross-sectional $(63 \%)$ studies of couples $(70 \%)$, with a just over half of the studies $(55 \%)$ utilizing predominantly White samples of participants averaging between 30 and 40 years of age (59\%). This body of work was largely informed by self-report survey (69\% of studies) and observational methods $(17 \%)$ with the remaining studies equally divided between those incorporating daily diary (7\%) and qualitative methods (7\%). As suggested by others (Fincham \& Beach, 2010), negative dimensions of marital behavior continued to be a popular line of inquiry during this first decade of the twenty-first century representing $55 \%$ of the articles published on marital behavior. Twenty-three percent of the studies focused on spouses' negative behavioral exchanges utilized observational methods to assess spouses' behavior in marriage. Marital conflict and related dimensions of discord (i.e., hostility, negativity, verbal aggression, demand-withdrawal cycles) continued to dominate the focus on negative marital behavior, but the decade also ushered in increased attention to intimate partner violence (e.g., Browning, 2002; Frye \& Karney, 2006; Lawrence \& Bradbury, 2007; O'Leary \& Slep, 2006) and infidelity (e.g., Atkins \& Kessel, 2008; Previti \& Amato, 2004; Whisman, Gordon, \& Chatav, 2007).

In contrast to past critiques suggesting that scholars have largely ignored positive marital processes in favor of a focus on marital conflict (Fincham, Stanley, \& Beach, 2007), 45\% of the articles sampled from the first decade of the new millennium focused on positive dimensions of marital behavior and included such varied topics as the provision of social support in marriage, forgiveness, affection, empathy, emotion work, commitment, emotional responsiveness, sensitivity, and connectedness (e.g., Curran, Hazen, Jacobvitz, \& Sasaki, 2006; Cutrona, Shaffer, Wesner, \& Gardner, 2007; Fincham, Paleari, \& Regalia, 2002; Gordon, Hughes, Tomcik, Dixon, \& Litzinger, 2009; Laurenceau, Barrett, \& Rovine, 2005). Furthermore, several studies focused on both positive and negative marital processes (DeLongis, Capreol, Holtzman, O'Brien, \& 
Campbell, 2004; Fincham, Beach, \& Davila, 2007) to better understand the relationship between them as well as their interactive effects on marital and personal well-being. Overall, this body of work addressing potential marriage-enhancing behaviors was largely survey based, with only $13 \%$ utilizing observational methods to study positive dimensions of marital processes.

\section{Marital Stability}

As in prior work, studies of marital stability in the past decade primarily examined factors predicting marital disruption in the form of divorce. A small group of studies also examined marital separation, with some scholars operationalizing marital disruption as either the occurrence of separation or divorce (Dush, Cohan, \& Amato, 2003; Zhang \& Van Hook, 2009) and others examining separation or the timing of separation as an independent outcome (Kurdek, 2002; Osborne, Manning, \& Smock, 2007). Theoretically informed by interactional and process models of divorce (Gottman, 1993; Pasley, Kerpelman, \& Guilbert, 2001), several scholars examined aspects of divorce proneness as outcomes of interest (e.g., thoughts of divorce; Amato \& DeBoer, 2001) or moderators of the association between various predictors and marital disruption (e.g., disenchantment; DeMaris, 2007). Family studies journals (i.e., Family Relations, Journal of Marriage and Family, Journal of Family Issues) and the Journal of Family Psychology were the primary outlets (98\%) for scholarship on marital stability. Slightly more than half $(53 \%)$ of the empirical literature was based on studies utilizing samples of married individuals (rather than couples), and $75 \%$ of the studies utilized longitudinal data. Sixty percent of the studies included diverse (e.g., Michigan Early Years of Marriage Study) or nationally representative US (e.g., NLSY, NSFG, NSFH, PSID) and non-US samples (e.g., National Family Health Survey of India; Bose \& South, 2003) of spouses who were in their early 20 s, on average, at Time 1.

\section{Marital Satisfaction}

Marital satisfaction, or spouses' subjective evaluations of their marriage, continues to be a topic of interest across academic disciplines. Although the Journal of Family Psychology published the greatest percentage of articles (33\%) of any single journal sampled, the remaining body of research on marital satisfaction spanned disciplinary boundaries and was found in journals serving scholars in family studies, close relationships, communications, and sociology. Studies utilizing samples of married couples represented the bulk of the empirical literature on marital satisfaction published in the past decade (80\%), with $63 \%$ conducted with predominantly White samples. Studies of younger married couples (i.e., in their $20 \mathrm{~s}$, on average) represented $46 \%$ of this body of work, and $40 \%$ of the research focused on couples in their 30s and $40 \mathrm{~s}$, on average. Research designs were equally likely to be cross-sectional or longitudinal. Marital satisfaction was treated as the outcome of interest in the majority of articles sampled with most studies operationalizing marital satisfaction as a global evaluation of how happy or satisfied spouses were with the marriage.

\section{Other Dimensions of Marital Quality}

The category of marital quality-other emerged during the content analysis to best represent articles that addressed spouses' subjective evaluations of or feelings about the marriage that 
didn't quite map onto global assessments of satisfaction per se. For example, some studies focused on spouses' subjective feelings of belonging and love in the marriage (e.g., Claxton \& Perry-Jenkins, 2008), whereas others operationalized marital quality as an overarching construct that included individual items assessing spouses' perceptions of a variety of interrelated aspects of marriage including satisfaction, behavior, trust, commitment, admiration, and perceptions of marital difficulties (e.g., Bryant, Conger, \& Meehan, 2001; Davey \& Szinovacz, 2004). Other authors purposefully examined unique patterns of association between predictor variables and several different dimensions of marital quality (e.g., marital love, feeling understood by one's partner, satisfaction with various domains of marriage) in the same study (e.g., Claxton \& PerryJenkins, 2008; Helms, Proulx, Klute, McHale, \& Crouter, 2006). Heeding prior calls for conceptual clarity regarding the construct of marital satisfaction (Bradbury, Fincham, \& Beach, 2000; Huston, 2000), most scholars studying marital quality were careful to distinguish spouses' cognitive evaluations regarding the degree to which they were happy or satisfied with their marriages (i.e., marital satisfaction) from their characterization of marital behaviors or other beliefs about or feelings associated with their marriages or partners. Furthermore, when combining various dimensions of marriage into a single construct, researchers were careful to label the construct broadly, choosing terms such as marital success, quality, or solidarity, rather than marital satisfaction, to better reflect the multifaceted nature of their measurement. It should be noted, however, that authors who utilized this strategy did not address earlier concerns regarding the use of nonstandard measures and the extent to which their findings can be integrated with the larger literature (Bradbury et al., 2000). Most studies of marital quality were published in family studies journals $(85 \%)$, and all were quantitative. Fifty-eight percent utilized samples of married couples, whereas $42 \%$ were studies of married individuals. Studies were evenly divided between those using White or predominately White samples and studies including diverse, non-US, or nationally representative samples (i.e., $48 \%$ and $47 \%$, respectively). Crosssectional studies predominated $(58 \%)$ as did studies of spouses in their 30 s and $40 \mathrm{~s}$, on average $(69 \%)$.

\section{Summary}

Results of the content analysis highlight the general patterns of publication in the past decade and show the study of marital behavior continues to be important to contemporary scholars. Most likely in response to earlier critiques, a focus on more positive marital transactions that are believed to sustain long-term marriages was found including such topics as marital commitment, forgiveness, and displays of affection. Interest in negative dimensions of marital transactions expanded in the past decade beyond marital conflict and problem-solving to include intimate violence, psychological aggression and control, and infidelity. Although these latter topics did receive some attention in past decades, the scope of the work failed to account for the complexity of these relationship phenomena or the contexts in which these problematic behaviors occur (Fincham \& Beach, 2010). Advances in the study of marital stability were informed by process models of marital dissolution that moved the focus from simply predicting static marital status variables (i.e., separated, divorced, married) to better understanding correlates of divorce proneness (e.g., disenchantment with the marriage, thoughts of divorce, etc.). In addition, the extent to which various dimensions of divorce proneness moderated the associations between known marital risks and later divorce were explored. Previously treated as interchangeable constructs, the study of marital satisfaction and other dimensions of marital quality were 
conceptually distinguished in the past decade. The majority of scholars in the twenty-first century were careful to conceptualize marital satisfaction as spouses' global cognitive evaluations of how happy or satisfied they were in the marriage, whereas marital quality became the new umbrella term used to capture the variety of affective and cognitive appraisals that more fully account for the thoughts and feelings spouses have about their marriages.

With the exception of research on marital stability in which $75 \%$ of the studies were longitudinal and $60 \%$ utilized diverse, nationally representative, or non-US samples, studies utilizing crosssectional methods and predominantly White samples characterized over $50 \%$ of the research reviewed for the content analysis. Studies of marital stability were more likely to employ samples of married individuals than were those focused on marital behavior, satisfaction, and marital quality. Most likely reflecting the dyadic nature of many of the research questions addressed in these latter content areas, the majority of studies that addressed some aspect of marital behavior, satisfaction, and quality were conducted with samples of couples (i.e., 58$70 \%$ ). Whereas the study of marital behavior was predominated by cross-sectional research, a more even distribution of cross-sectional and longitudinal methods was found in the marital quality and marital satisfaction literature. Across all topics, and with only a few exceptions, the marital experiences of spouses over the average age of 50 were largely overlooked, underscoring the importance of future work on long-term marriage and romantic relationships in later adulthood (see Fingerman \& Hay, 2002; Tucker \& Crouter, 2008).

\section{Huston's Three-Level Model of Marriage as a Frame for the Literature}

An important theoretical contribution to emerge on the advent of the twenty-first century was Huston's three-level model of marriage. Huston's (2000) model emerged from a critique of the extant marital scholarship in which he asserted that marital researchers have typically focused on one dimension of a much larger causal system, resulting in an incomplete and perhaps inaccurate depiction of marriage. Juxtaposing research that focused on behavioral exchanges between spouses and their links with marital quality and studies that adopted a broader, macroenvironmental lens, Huston argued that:

The propensity of researchers to use either an unfocused lens or to zero in on narrow and isolated slices of the larger marital terrain has produced a literature on marriage that provides limited insight into how marriages actually work. Such a state of affairs also has undermined the development of sophisticated theories designed to link the qualities and dispositions of the spouses to features of the marriage relationship and has hindered efforts to examine how the ecological context influences the details of couples' day-today married life. (p. 299)

At the crux of Huston's critique is the assertion that social scientists have failed to adequately anchor their work in theories relevant to everyday experiences encountered in marital relationships. Some have argued that this oversight stems from a preference for basic over applied research (Bradbury, 2002), individualistic disciplinary orientations (Berscheid, 1999), and biases that underestimate the effects of forces external to the couple for marital behavior, quality, and stability (Karney, 2007). Regardless of the cause, inattention to theory has been a recurring criticism of marital research since its inception in the early twentieth century as 
recounted in earlier editions of the Handbook. Calls for broader, more integrative frameworks to bridge basic and applied research as well as the lived experiences of married couples were underscored most recently by Carroll, Knapp, and Holman (2005) in the Sourcebook of Family Theory and Research. In a commentary of this work, Adams (2005) suggests that pointing out inadequacies in theory development is one thing; adequately theorizing the complexity of marriage is another. Fortunately, Huston followed his critique of the literature with a detailed account of an integrative conceptual framework for understanding marital relationships in the twenty-first century which has been further developed and refined for application to diverse couples in the new millennium (see Helms et al., 2011).

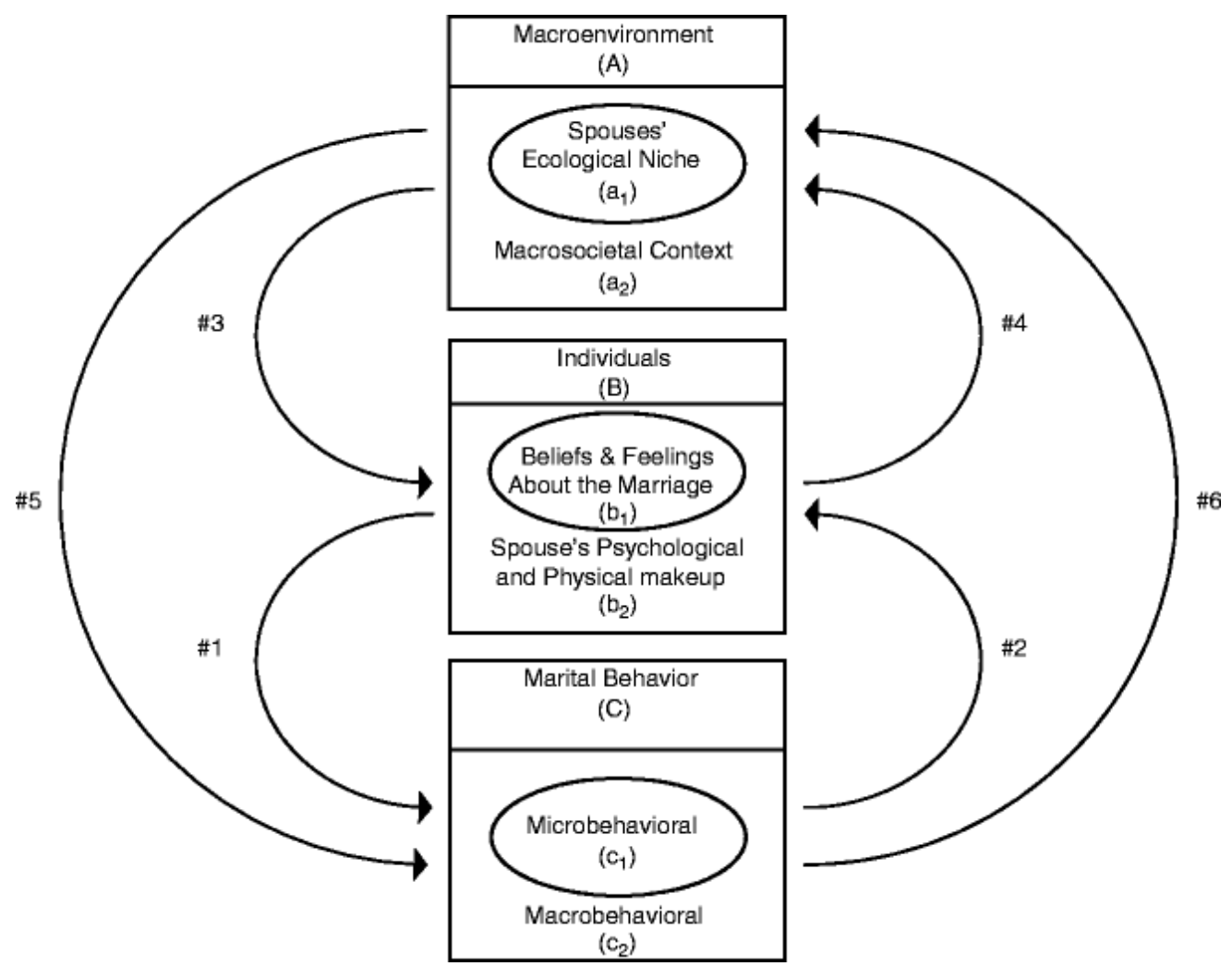

Fig. 11.1. Adapted three-level model for viewing marriage (From Huston (2000), p. 300. Adapted by Helms, Supple, and Proulx (2011) with permission of the author)

At the most basic level of his integrative model, Huston (2000) identifies three central elements to understanding marriage: marital behavior, individual properties, and the macroenvironment (see Fig. 11.1). Implied in his discussion of these interdependent factors is the assumption that they operate together to affect the course of marriage, and ultimately marital stability. The description herein reflects Huston's conceptualization of these three central elements and incorporates minor adaptations to the model introduced by Helms and her colleagues (2011) in their application of the model to immigrant Mexican couples. In the pages that follow, the central elements and associated principles of the model are explained and further illustrated with current research. Rather than offering an exhaustive review of the literature, this approach highlights research that aligns with the conceptual model presented and calls attention to domains of inquiry that will be important to pursue in future work. In this way, an underlying goal of this 
chapter is to strengthen scholarly work on marriage in the twenty-first century by encouraging theoretically grounded research that accounts for the complexity of couples' lived experiences.

\section{Marital Behavior (Box C)}

Of central focus in the model, Box C, Marital Behavior, represents intra-dyadic behavioral exchanges and patterns that characterize marital experience and a great deal of the literature on marriage as reviewed above. Considered important for a thorough understanding of marriage and "the foundation on which careful descriptions of marriage relationships can be built" (Huston, 2000, p. 300) are ( $\left.c_{2}\right)$ macrobehavioral patterns such as spouses' companionship, leisure, the divisions of housework, and (for married parents) the division of parenting responsibilities and childcare, and $\left(\mathrm{c}_{1}\right)$ microbehavioral exchanges that include expressions of hostility, warmth, and other communication patterns that are nested within macrobehavioral patterns of interaction (Helms et al., 2011; Huston, 2000). Huston underscores the nested nature of micro- and macrobehavioral interactions in the model and suggests that "macrobehavioral activities ... provide the larger ecological context within which microbehavioral marital behaviors are played out" (p. 306). Microbehavioral exchanges within couple dyads continue to dominate the marital behavior literature with less attention given to the macrobehavioral interactional patterns within which microbehavioral exchanges occur.

Usually examined in separate studies, scholars have yet to adequately explore how microbehavioral patterns of interaction are related to the macrobehavioral patterns of interaction in which spouses engage (or fail to engage). For example, how do microbehavioral interactions such as a couple's ability to resolve problems with one another or effectively offer support relate to the amount of time they spend with one another (i.e., companionship), their individual and joint leisure pursuits and the manner in which they divide the everyday demands of caring for children and managing other household responsibilities? Could it be that patterns of daily activity, such as the division of housework, might predict spouses' expression of negativity or warmth in a marital problem-solving task? Or perhaps the couples' marital communication patterns may alter how much time they spend with one another or their willingness to share in family work including housework and coparenting. Contemporary advice columnists and popular press books endorse the view that spouses' ability to get along is linked to the mundane, and yet, empirically, there is little evidence for this assertion, nor do we adequately understand the link. With an emphasis on understanding the everyday experiences of spouses' marital lives, Huston challenges scholars to further explore this overlooked link and suggests that marriage will not be fully understood until they do.

Grounding their work in Huston's (2000) three-level model of marriage, several twenty-first century scholars are leading the way in examining this promising area of research. For example, associations between marital conflict $\left(\mathrm{c}_{1}\right)$ and spouses' shared religious activities $\left(\mathrm{c}_{2}\right.$; Curtis \& Ellison, 2002) and couples' leisure ( $\left.c_{2}\right)$ across the transition to parenthood (Claxton \& PerryJenkins, 2008) have been the focus of recent inquiry. In addition, although scholars have been careful to acknowledge the possibility of a reciprocal causal relationship between micro- and macrobehaviors in marriage, to date this body of work has been theoretically framed as a test of the effect of macrobehavioral marital patterns on microbehavioral exchanges. For example, in their short-term longitudinal study of 127 married and cohabiting working-class couples 
transitioning to parenthood, Claxton and Perry-Jenkins examined how the prospective association between spouses' individual and joint prenatal leisure pursuits (i.e., Time 1) predicted marital conflict 1 year postpartum (i.e., Time 4). The authors hypothesized that shared leisure would be negatively associated with conflict, and leisure activities engaged in alone or with people other than the spouse would be positively associated with conflict. Findings provided partial support for the hypothesized relationships and suggested that gender may moderate the association between micro- and macrobehavioral interaction. That is, for wives, more shared leisure with husbands prior to the birth of their first child predicted less marital conflict 1 year postpartum, whereas for husbands, more independent leisure prior to their firstborn's birth was linked to marital conflict when the baby was 1 year old. Findings such as these offer empirical support for Huston's theoretical assertion that macrobehavioral patterns of interaction in marriage set the stage for microbehavioral exchanges. Yet much remains unknown regarding the degree to which any number of micro- and macrobehavioral exchanges may be linked, including the exploration of more positive micro-exchanges in marriage. Furthermore, Huston's premise that the link between micro- and macrobehavioral dimensions is reciprocal remains unexplored. Results supporting a reciprocal association over time between spouses' macrobehavioral patterns of interaction and their subjective evaluations of marriage $\left(b_{1}\right.$; e.g., marital satisfaction), however, suggest that further exploration of the reciprocal link between macrobehavioral interactions in marriage and microbehaviors may be warranted (Crawford, Houts, Huston, \& George, 2002).

\section{Individuals (Box B)}

Huston draws an important distinction between marital behavior (a relationship property) and spouses' individual characteristics, and their beliefs and feelings about their marriage and each other through his inclusion of box B. Because this distinction is often blurred in marital research, scholars miss an important opportunity to examine how spouses' individual properties and belief systems (Box B) are linked to their interactions in their marital relationship (Box C). By conceptually distinguishing marital experiences (Box C) from spouses' personal qualities and their beliefs, attitudes, feelings, and evaluations of their marriage (e.g., marital satisfaction and other dimensions of marital quality, Box B), Huston underscores the role of the individual in shaping and responding to marital experiences. In this way Huston lays the groundwork for greater precision in the empirical study of marriage and its measurement - an area of concern that has been voiced for decades (see Fincham \& Bradbury, 1987; Kelley et al., 1983).

Entitled Individuals, Box B has two distinct, yet interrelated, components: $\left(\mathrm{b}_{2}\right)$ spouses' physical and psychological makeup including intrapersonal qualities such as their psychological characteristics, cultural and gendered orientations and values, family background, genetic makeup, and physical and mental health; and $\left(b_{1}\right)$ spouses' feelings and beliefs about their marriage and one another in their respective marital roles (e.g., spouse, parent, provider). Huston further differentiates spouses' beliefs and feelings about the marriage $\left(b_{1}\right)$ by distinguishing spouses' partner-specific cognitive schemas (e.g., attributions about spouses' behavior) from their more general evaluations of the marriage and feelings associated with it (e.g., marital satisfaction, feelings of love, and other dimensions of marital quality). Separating these constructs theoretically adds yet another layer of complexity and suggests that partner-specific beliefs (e.g., attributions about spouses' behavior) and feelings or thoughts about the marriage 
(e.g., marital satisfaction) are reciprocally related and both are nested in the context of spouses' physical and psychological makeup $\left(\mathrm{b}_{2}\right)$.

In Huston's (2000) careful explication of spouses' marriage-specific beliefs and feelings, he differentiates more precisely among the array of psychological forces that potentially link spouses to one another than previously proposed theoretically or empirically in a single model. For example, Huston encourages scholars to think more broadly than the limits of marital satisfaction (e.g., spouses' global cognitive evaluations about marriage; $b_{1}$ ) and suggests that there is much to gain in predicting marital stability and longevity by examining a broader array of spouses' feelings associated with marriage and one's partner including love, commitment, understanding, admiration, respect, and trust (see Amato, 2007; Johnson, Caughlin, \& Huston, 1999; Kelly \& Floyd, 2006; Stets, 1993; 1995; Stets \& Hammons, 2002). More recently, Huston and Melz (2004) and Fincham, Stanley, and Beach (2007) have suggested that positive and negative feelings and beliefs associated with the marriage can and do coexist and create emotional climates that are generally warm (i.e., high positive, low negative), distressed (i.e., low positive, high negative), stormy (i.e., high positive, high negative), or bland (i.e., low positive, low negative). This $2 \mathrm{D}$ view of the emotional climate of marriage expands the focus of the current empirical literature beyond distressed versus non-distressed couples to couples who may have emotionally neutral marriages or marriages characterized by the drama that unfolds when strong positive and negative feelings coexist (Huston \& Melz, 2004). Capturing the array of feelings associated with marriage across dimensions can be challenging empirically (Amato, 2007), but instrument development and measurement studies have begun (Fincham \& Linfield, 1997; Mattson, Paldino, \& Johnson, 2007), and qualitative work is beginning to emerge that can further inform these efforts. Once links between these additional dimensions of marital quality and marital stability are well established, understanding specific marital behaviors in marriage (Box C) that gives rise to marriage promoting feelings and beliefs (Box B) will be important to explore.

Huston underscores that spouses' relatively stable physical, psychological, and social attributes are intricately linked with their beliefs, feelings, and evaluations associated with their marriage. For example a history of psychopathology (e.g., Beach, 2000), marital functioning in spouses' families of origin (e.g., Amato \& Hohmann-Marriott, 2007; Hetherington, 2003), premarital cohabitation (Stanley, Rhoades, \& Markman, 2006; Tach \& Halpern-Meekin, 2009), and early experiences in one's family of origin (e.g., Sroufe, Egeland, Carlson, \& Collins, 2005; Umberson, Williams, Powers, Liu, \& Needham, 2005) have all been linked to spouses' perceptions of marital quality. Clearly, links between spouses' personal qualities and their views of marital quality have been studied for decades and many are well documented (see Bradbury et al., 2000; Fincham \& Beach, 2010, for reviews). By characterizing spouses' marital evaluations and feelings about the relationship and each other as an individual property nested within spouses' own psychological and physical makeup, however, the model makes explicit not only that a link exists between these constructs but suggests a reciprocal relationship between them. In short, Huston challenges scholars to explore not only the way in which husbands' and wives' personal qualities can color their perceptions of marital quality but also how spouses' beliefs and attitudes about their marriage and partner can influence dimensions of spouses' own and their partners' personal well-being and values. 
Aligning with Huston's (2000) theoretical framework and made possible by methodological and analytic advances, the causal ordering of spouses' personal qualities and perceptions of their marriage and the possibility of bidirectional effects between them over time has been a focus of inquiry in the past decade. For example, in a recent meta-analysis of literature addressing the link between marital quality and personal well-being (i.e., assessed as both psychological and physical health), the longitudinal association between marital quality and personal well-being was found to be stronger when well-being was treated as the dependent variable than when it was examined as a predictor of marital quality (Proulx, Helms, \& Buehler, 2007). These results provided support for the marital discord model of depression which argues that marital dissatisfaction can lead to increased risk for depression by depleting important marital resources such as spousal support, warmth, dependability, and cohesion and increasing negativity in the marriage (Beach, Sandeen, \& O'Leary, 1990). Support also exists, however, for individual differences in marital quality. For example, recent work utilizing a genetically informed twin design suggests that genetic factors may play a role in shaping spouses' marital quality (Spotts, Prescott, \& Kendler, 2006). As suggested by Huston, many scholars support the proposition that links between individual characteristics and marital quality are bidirectional and recent tests offer support for this premise. For example, bidirectional influence between spouses' attributions about their partners' negative behavior and marital satisfaction was found in longitudinal studies of early marriage using growth curve analysis and cross-lagged modeling (Fincham, Harold, \& Gano-Phillips, 2000; Karney \& Bradbury, 2000). No support was found for the view of attributional style as a stable trait, and instead results suggested that the influence between spouses' negative attributions about their partner and their perceptions of marital satisfaction covary over time and exhibit bidirectional effects. Furthermore, and perhaps more importantly, the strength of this association between spouses' negative attributions and marital satisfaction may be most robust for couples who later dissolve their marriages (Karney \& Bradbury).

Another benefit of conceptually distinguishing spouses' individual properties (Box B) from their marital experiences (Box C) is that it underscores the possibility of within-couple incompatibilities and discrepancies in perceptions of marital quality as well as the potential for crossover effects from one spouse to another. Here, compatibility theories of marriage inform Huston's (2000) model and suggest that congruence in husbands' and wives' personal qualities and perceptions of the marriage is important for a mutually satisfying relationship. Accordingly, Huston calls attention to the importance of the dyadic patterning of spouses' individual qualities and marital evaluations as well as the ways in which spouses exert influence on one another. In short, the interdependence, patterning, and potential crossover effects of spouses' personal qualities and their marital evaluations are emphasized along with potential within-couple variations in the "match" of spouses' qualities and views of the marriage and each other.

Underscoring the importance of a dyadic approach to the study of marriage, recent work has examined the prospective association between couple profiles of spouses' sex-typed personal qualities and attitudes toward breadwinning and husbands' and wives' perceptions of marital quality over time (Helms et al., 2006; Helms, Walls, Crouter, \& McHale, 2010). In this work, common couple configurations based on patterns of spouses' sex-typed qualities and attitudes toward breadwinning were identified, specific couple profiles linked with risk for lower marital well-being were discovered, and insights into aspects of partners' personal qualities and beliefs that may be protective for their evaluations of marriage were emphasized. In addition, short-term 
longitudinal studies employing daily diary, computer-assisted data collection methods across a series of days and the Actor Partner Interdependence Model (APIM) as an analytic strategy (see Kenny, Kashy, \& Cook, 2006) provide a unique opportunity to examine potential crossover effects between husbands and wives. The transmission of emotion from one spouse to another, individual factors that strengthen the transmission of emotions, and subsequent links with marital satisfaction have all been the focus of scientific inquiry in the past decade (e.g., Schoebi, 2008). With increased application of pattern analytic and person-centered approaches (e.g., cluster analysis, mixture models including latent class analysis, profile analysis, and growth mixture models), Huston's theoretical assertions regarding the importance of the patterning of spouses' individual characteristics and their links with marital quality can be better examined (see Whiteman \& Loken, 2006). Furthermore, with analytic strategies such as the APIM, crossover effects within marital dyads from one spouse to another can now be explored with greater precision than ever before.

\section{The Macroenvironment (Box A)}

Some fragile relationships survive forever because they never encounter a relationshiptoxic environment, but some very strong relationships dissolve - not because they were not close, or committed, or loving - but because fate, or the partners' ignorance of the vulnerability of their relationships to external forces, or perhaps even uninformed governmental policy decisions put their relationships in harm's way (Berscheid, 1999, p. 265).

Perhaps the greatest contribution of the first decade of research on marriage in the twenty-first century is the increased attention to factors external to the marriage and individual spouses that play a role in supporting or undermining marital and individual functioning. Historically, the marital literature has focused on a relatively privileged and narrow slice of the population pie. As twenty-first century scholars began to examine the marital experiences of couples beyond the White and middle class, however, it became apparent that context does indeed matter (Fincham $\&$ Beach, 2010). More specifically, environments external to marriage were found to shape the content of spouses' interactions, their ability to interact effectively, their evaluations of marriage, and ultimately whether or not they remained married (see Huston \& Melz, 2004; Karney \& Bradbury, 2005).

The final element in the adapted model, the Macroenvironment (Box A), accounts for the various contexts in which individuals and their marital behavior are embedded, including $\left(\mathrm{a}_{2}\right)$ the larger macrosocietal context and $\left(\mathrm{a}_{1}\right)$ spouses' ecological niches (i.e., the social and physical settings in which spouses function on a daily basis) (Helms et al., 2011; Huston, 2000). In this box, spouses' ecological niches represent proximal dimensions of the social environment (e.g., parent-child relationships, relationships with extended kin, co-workers, friends, community members) and the physical environment spouses inhabit on a daily basis (e.g., housing, workplace, neighborhood, proximity to kin and work). These ecological niches are nested within the larger macrosocietal context that includes sociohistorical location, dynamic dimensions of culture such as norms and values endorsed by members of a cultural or subcultural group, and overarching socioeconomic conditions (e.g., laws, policies, physical resources, economic opportunity) that have the ability to either facilitate or inhibit individual development and marital 
functioning. The two components of the macroenvironment are interrelated in that the macrosocietal context can alter spouses' ecological niches and spouses' ecological niches are often the medium through which macrosocietal dimensions of context are articulated, reinforced, or undermined. Research in this area, however, has focused primarily on direct links between aspects of spouses' ecological niches (e.g., neighborhood conditions, social network support, the parent-child relationship) and other components of the larger model (e.g., marital behavior, marital satisfaction). Although effects of macrosocietal conditions are often i mplied in discussions of the links between marital quality and ecological niche elements such as neighborhood poverty and social capital, reliance on survey methods has limited empirical tests for Huston's assertions regarding the role of the ecological niche in challenging or channeling macrosocietal dimensions of context to marital behavior (Bradbury et al., 2000).

The social environment. In their decade review of the marital satisfaction literature at the dawn of the twenty-first century, Bradbury et al. (2000) concluded that to better understand marital behavior and spouses' perceptions of marital quality, researchers need to pay greater attention to the relationships and nature of support that both partners obtain outside, as well as inside, the marriage. As Huston (2000) stated,

Usually ... researchers focusing on the dynamics of marital interaction study couples as two-person units, as if they rarely spent time together as part of a social group ... the centrality of spouses in each other's day-to-day lives, as well as their joint and independent involvement with friends and kin, reveal much about the nature of the spouses' marital relationship (pp. 300-301).

An increase in research on the social contexts in which marriage is embedded has emerged in the past decade with studies focused on how marital quality and behavior are associated with husbands' and wives' interactions with in-laws, parents, close friends, and children. Support for bidirectional effects between marital quality and spouses' relationships with friends and extended family members has been found in longitudinal studies testing cross-lagged analytic models and further substantiated with qualitative accounts (Beaton, Norris, \& Pratt, 2003; Bryant et al., 2001; Kearns \& Leonard, 2004; Serewicz \& Canary, 2008). For example, difficulties in extended family relationships have been shown to erode spouses' marital satisfaction and contribute to marital instability, even in relatively long-term marriages. In addition, the quality of these same marriages has been prospectively linked to conflict with in-laws for husbands, suggesting that husbands in long-term marriages that are satisfying are less likely to have difficulties with their in-laws than husbands in less satisfying marriages (Bryant et al., 2001). With the exception of the transition to parenthood literature that has demonstrated that marriages change with the addition of children (see Bradbury et al., 2000, for a review), surprisingly little attention has been given to the effects of children on marriage. Although Huston (2000) draws attention to the role of children in marriage by including them as a part of spouses' ecological niche, the model does not explicitly incorporate how children's personal qualities, or elements of parent-child relationships, may influence marital behavior and quality - a substantive area often overlooked in marital and family research. Underscoring the central role that children and parent-child relationships occupy in many couples' lives, contemporary scholars are attending to how and under what conditions children's personal qualities, parent-child relationships, and marriage are linked across the life course (see Crouter \& Booth, 2003). This emergent body of 
literature has demonstrated how within-couple incongruence in husbands' and wives' differential intimacy and conflict with their first and second-born children covaries across the childrearing years with spouses' reports of marital quality (Kan, McHale, \& Crouter, 2008). Related studies also indicate how infants' sleep patterns and crying effect trajectories of their mothers' and fathers' marital quality across their first year of life (Meijer \& van den Wittenboer, 2007). Other investigators have identified the associations of the simultaneous impact of multigenerational bonds (Bengtson, 2001; Cullen, Hammer, Neal, \& Sinclair, 2009) and shared family rituals with husbands' and wives' reports of marital quality (Crespo, Davide, Costa, \& Fletcher, 2008).

The extent to which husbands and wives garner support from social network members specific to marriage and parenting and subsequent links to marital quality have also been a topic receiving attention. The marital implications of parents' reliance on one another, kin, and other close associates as sources of advice, guidance, caregiving, and emotional support regarding the routine transactions of marriage and parenthood have been documented across social classes in predominantly White populations (Helms, Crouter, \& McHale, 2003; Milardo \& HelmsErikson, 2000; Proulx, Helms, \& Payne, 2004). Actively engaging social network members in discussions about marital and parenting concerns has been linked to spouses' reports of marital satisfaction, love, and stability - particularly for wives who are members of White populations (Helms et al., 2003; Proulx et al., 2004). Recent work also suggests, however, that the strength of this association may be most robust in ethnic minority and lower income couples who must navigate marital and family relations against a backdrop of economic disadvantage and marginalization (Helms et al., 2011). Integrating this body of literature with earlier work suggests that actively seeking out spouses to discuss concerns in the domains of marriage and parenting is an important predictor of marital well-being for wives, often overshadowing husbands' instrumental contributions to housework and childcare (Erickson, 1993). Using spouses in this supportive manner also may counteract the adverse effects of economic pressure on marital evaluations (Simons, Whitebeck, Melby, \& Wu, 1994).

Acute and chronic environmental stressors. Of considerable focus in past decades has been the study of the impact of acute and usually traumatic stressors on couples' marital functioning (for a review, see Bradbury et al., 2000). These studies examined topics such as the death of a child, a natural disaster, or war and aspects of marriage that were affected by the event or buffered its impact. Unique to the twenty-first century is a focus on the marital experiences of married veterans returning from extensive deployments to Afghanistan and Iraq. Although the length of deployment was unrelated to marital dissolution for service members in most branches of the military (Karney \& Crown, 2007), PTSD, depression, and anxiety following deployment did appear to be linked to marital satisfaction, and PTSD symptoms, specifically, predicted marital aggression (see Fincham \& Beach, 2010, for a review).

Additional research complements this work by focusing on the way in which chronic, everyday stressors may interact with acute stressors to affect marital functioning. Defined as relatively minor ongoing stressors that occupy daily living (e.g., experiences at work, interactions with friends and family, physical environment stressors such as traffic jams and poor living conditions), chronic stressors were found to strengthen the association between acute stress (i.e., defined as major life events) and spouses' marital satisfaction over time suggesting that acute negative life events are more harmful to marriage when levels of chronic stress are high 
(Bradbury \& Karney, 2004). Evidence of crossover effects between husbands' and wives' experiences of chronic stress and their partners' evaluations of marriage has also been found under certain conditions. For example, the everyday hassles that wives experience have been shown to effect their husbands' evaluations of marriage in marital contexts characterized by negative conflict resolution styles, whereas husbands' stress from daily hassles impacts their wives' marital satisfaction only when wives themselves report high levels of chronic, daily stress (Neff \& Karney, 2007). Research focusing on these more frequent and continuous forms of stress suggests that such everyday hassles may be more important determinants of marital quality than major, but less frequent, life events. Accordingly, the aggregate effects of everyday hassles have the potential to compromise marital and individual well-being and even increase vulnerability to major life events (Helms, Walls, \& Demo, 2010).

Socioeconomic and work contexts. Historically, economic and work-related factors have received the most extensive attention as macroenvironmental contexts for marital functioning. Links between marriage and spouses' access to work-related resources such as income, occupational prestige, and social support have been documented (see Crouter \& Helms-Erikson, 2000, for a review) for primarily White and middle class couples. In addition, the nature of work itself, including occupational complexity and self-direction, has been linked to the distribution of power in marriage and the way couples divide family work (e.g., Klute, Crouter, Sayer, \& McHale, 2002). Additional studies have focused on the impact of short-term work stressors and tensions that spill over into marital life. Grounded in a dyadic approach, these studies draw attention to what we know about the transmission of work stress to marital functioning for men and for women, and whether husbands and wives respond in the same way to their spouse's experience of day-to-day stress on the job (Perry-Jenkins, Repetti, \& Crouter, 2000). Seminal work on marriage in the context of economic stress by Conger, Rueter, and Elder (1999) demonstrated prospective links between predominantly White, rural spouses' perceptions of economic pressure and marital distress via individual distress. Furthermore, the association between economic pressure and individual distress was most pronounced for spouses with few social supports outside the marriage, underscoring the ways in which various macroenvironmental contexts may interact to effect individual and marital well-being.

The links between job loss, economic strain, and marital quality continue to be of interest to twenty-first century scholars (Howe, Levy, \& Caplan, 2004). Adaptations of the Conger and colleagues family stress model have been used with increasingly diverse populations via interactions of financial strain with other dimension of the macrosocietal context (e.g., racial discrimination, culture) relevant to families of color (Cutrona et al., 2003; Helms et al., 2011; Murry et al., 2008). As the larger work and family literature has shifted its focus beyond the predominantly White and middle class to an interest in the work experiences of working class, low-income and ethnic minority families (see Crouter \& Booth, 2004), new content areas have emerged in the twenty-first century that show particular promise in furthering our understanding of the work-marriage link. For example, with the emergence of the 24/7 service economy, the effects of shift work and nonstandard schedules on marital relationships have come into focus with early work in this area suggesting that spouses who work nonstandard work schedules in part to balance the demands of work and family may experience unanticipated declines in personal and marital well-being (Barnett, Gareis, \& Brennan, 2008; Presser, 2000). Although no published studies addressed the links between work contexts and marital relationships for Latino 
or other immigrant groups in the literature reviewed here, a body of work in this area is emerging. Contemporary scholars of immigrant family life suggest that the effects of structural inequalities including underemployment, physical demands of work, long work hours and racism in the workplace will be important areas of inquiry to explore to better understand the marital experiences of couples across the diverse demographic landscape of the 21 st century (Updegraff, Crouter, Umaña-Taylor, \& Cansler, 2007).

Community and neighborhood contexts. A final area of focus involves attention to those dimensions of the macroenvironment that are slow to change and can have far reaching consequences for the marital experiences of entire cohorts of couples. For example, the sex composition of local marriage markets has been studied to better understand how living in an environment with greater or fewer spousal alternatives is linked with marital quality and divorce proneness (Trent \& South, 2003). In part in response to racial disparities in rates of marriage and marital dissolution, there has been an increased focus on the community contexts in which African American marriages are embedded and their implication for marital well-being (Bryant \& Wickrama, 2005; Wickrama, Bryant, \& Wickrama, 2010). This body of work has explored the ways in which community adversities and resources influence whether and how couples form their relationships, the behaviors they engage in when married, their perceptions of marital quality, and the longevity of their marriages. Results from these studies suggest that living in communities characterized by economic disadvantage and high rates of residential mobility is harmful for African American couples' marriages (Bryant \& Wickrama, 2005; Cutrona et al., 2003), whereas higher percentages of minorities in the community can potentially protect marriage via the informal supports community contacts provide to husbands and wives (Bryant \& Wickrama, 2005). As evidenced here, most promising in this line of work are those studies that consider the interaction of multiple dimensions of couples' macroenvironments and the mechanisms through which community level adversities and resources operate to either protect or undermine marital functioning. For example, in a nationally representative study of midlife married and cohabiting partners, Voydanoff (2005) found that the protective effects of affective community resources (i.e., sense of community, neighborhood attachment, and support) were linked to marital satisfaction via the reduction of tensions related to the competing demands of work and family. The extent to which spouses are exposed to racially based discrimination in their communities is another potential mechanism explaining links between community context and marital experience (Cutrona et al., 2003).

Summary and caveats. The vast majority of studies that consider the links between marriage and spouses' ecological niches and the larger macrosocietal context emphasize the impact of the macroenvironment on marriage (e.g., path 5) and downplay the active role that spouses play in selecting their environments (e.g., path 4; path 6). The choices spouses make independently and jointly in such areas as education, jobs, workplace, children, friends, extended family contact, geographic location, housing, community involvement, etc., are in part based on their own individual properties (Box B) including their psychological predispositions, physical and mental health, and family background. Spouses' individual differences also play a role in how they respond to and the extent to which they engage various dimensions of the larger macroenvironment, and, consequently, their marriages are likely to be differentially affected by otherwise similar contexts (e.g., paths 3-1). No sophisticated statistical model can completely remove the presence of naturally occurring selection effects, nor can all possible variation due to 
individual differences be controlled. Because these factors are intertwined in the everyday lived experiences of couples, statistically removing them from the equation is ill advised. Instead, Huston (2000) offers a conceptual model that incorporates the complexities of the selection process into and out of various dimensions of the macroenvironmental context as well as individual differences in the links between the macroenvironment and marital functioning and, in so doing, underscores this often overlooked, yet important, research domain.

\section{Linking Marital Behavior, Individuals, and the Macroenvironment to Inform Future Research}

Perhaps the greatest contribution of Huston's (2000) model is the attention to the multilayered, interdependent causal pathways (i.e., paths 1-6) within and between each element of the model. Both the direct and indirect paths to and from marital behavior remind us of the complex and dynamic nature of individuals, marital behavior, and the macroenvironment and provide a useful visual heuristic of the bidirectional links that potentially exist. In addition, the focus on potential moderating and mediating variables rather than simple main effects is particularly applicable to the study of marriage in the twenty-first century - a time when the most important advances are likely to come in the form of understanding how multiple sources of influence interact. Huston's conceptual framework provides guidance for contemporary marital researchers asking complex questions that require moving beyond a focus on one or two predictor variables (see Bradbury, 2002). Perhaps most importantly, the model pathways provide specific guidelines for how a variety of factors may interact with marital behavior or perceptions of marital quality, and in so doing, avoid the inevitable criticisms that arise when researchers simply add more predictor variables to the mix without carefully thinking through the relationships between them (Karney, 2007).

As demonstrated by paths 3 and 5, individuals and marital behavior are embedded within a larger macroenvironmental context and can be directly affected by macrosocietal trends and historical events as well as the daily activities taking place in spouses' ecological niches. For example, as the onset of the first major economic recession in the new millennium intersected with a push for more responsible use of natural resources, national news featured the closing of the Pilgrim's Pride chicken processing plant in Siler City, NC. The plant employed 830 workers, the majority of whom were immigrant husbands and wives from Mexico (Yeong, 2008). High feed costs attributed to increased federal subsidies for ethanol blenders were cited as the primary reason for the plant closing. The closing of this chicken plant devastated the Latino community in Siler City and is just one example of how changes in the macrosocietal context (i.e., increased federal subsidies for alternate fuel sources) have a direct impact on couples by altering the ecological niches (e.g., the workplace) in which they function and on which they are dependent for economic stability.

In addition to these direct influences demonstrated in the model, macroenvironmental factors often exert indirect influence on the marital relationship via their effects on the husband, the wife, or both partners (path 3 to path 1). In the example presented above, the stress of job loss on the husband, the wife, or both is likely to produce anxiety and depression which, in turn, leads to increased marital conflict (Conger et al., 2002). Spouses' personal qualities may moderate the impact of the macroenvironmental stressor, however, by buffering or exacerbating the effect on 
the marriage. For example, the effect of job loss on spouses' marital behavior may be attenuated by personal characteristics such as high levels of self-esteem, or amplified if either the husband or wife is already distressed about the marriage, has a propensity towards violence, or is in poor health (McKee-Ryan, Song, Wanberg, \& Kinicki, 2005).

Alternatively, the macroenvironmental context may demonstrate its greatest influence on individuals via difficulties created in their closest social ties, such as those found in marriage (path 5 followed by path 2). In this sequence of paths, marital behavior can be treated as either a mediator between macroenvironmental conditions and individuals or as a moderator in its potential to diminish or amplify the effects of stressful conditions on spouses' personal qualities and perceptions of marital quality. In support of these theoretical propositions are results showing direct effects of the marital relationship on physical and mental health, as well as studies demonstrating how particular marital behaviors and strategies eliminate, reduce, or magnify direct associations between stressful contextual conditions and family members' physical and psychological well-being (e.g., Proulx et al., 2007; Wickrama et al., 2010).

Anchored in recent work documenting how negative marital exchanges alter dimensions of spouses' physiological makeup that are important for long-term health (Robles \& KiecoltGlaser, 2003), research emerging at the close of the first decade of the twenty-first century offers empirical support for marital behavior operating as a key mechanism linking macroenvironmental stress and individual well-being. For example, in a study of the marital experiences of 540 newly married African American couples, the link between husbands' perceptions of community disorder and spouses' depressive symptoms was explained by spillover (within spouse) and crossover effects of spouses' hostile marital exchanges (e.g., wives' hostile behavior to husbands' well-being and husbands' hostile behavior to wives' wellbeing) (Wickrama et al., 2010). Furthermore, partial mediation was supported for wives' hostile marital exchanges and both spouses' physical health. These results suggested that the stressors incurred by husbands' perceptions of adverse community conditions may affect both spouses' physical health via wives' expressed hostility in the marriage. In contrast, spouses' psychological well-being is compromised by both their own and their spouses' negative marital behavior. This promising early work examining the complex links between multiple dimensions of the threelevel model of marriage underscores that the marital dyad can be a critical point of entry for macroenvironmental stressors. Accordingly, the marital dyad serves either as a buffer against or a conduit for the transmission of stress to spouse's personal well-being and evaluations of the marriage.

Clearly both bidirectional and circular relationships between multiple layers of context are underscored in Huston's (2000) three-level model for viewing marriage. Although difficult to explore empirically, Huston acknowledges that individual properties influence the choices spouses make personally and as a couple regarding their physical environments. Moreover, in the collective, individuals and marriages alter the norms, laws, and policies characterizing the macrosocietal context (see path 2-4 and path 1-6, respectively). For example, financial contributions sent by Latino immigrants to family members residing in Mexico account for a substantial and increasing segment of the economy, representing $2.5 \%$ of Mexico's gross domestic product and ranking as the second largest source of foreign income after crude oil (World Bank, 2005). The practice of reserving and remitting income to extended families in 
Mexico begins as an individual or dyadic decision with direct implications for spouses' own ecological niches. Not only are immigrant couples' own ecological niches impacted by remitting funds, but the ecological niches occupied by recipient families in Mexico are affected as well. Finally, the collective result of this process is a macrosocietal change in the economic landscape of the receiving country.

Forward thinking scholars of marriage and other close relationships have a long history of posing complex questions and pushing the envelope of what researchers can explore empirically. At the advent of the twenty-first century - a time of significant variation in marital and family lifeHuston proposed a conceptual model to assist contemporary scholars in formulating research questions, launching programs of research, and advancing the study of marriage through a model that conceptualizes the myriad factors that interact with the marital experiences of diverse couples. A fundamental strength of Huston's (2000) model lies in its attention to the multilayered, interdependent, and causal pathways linking constructs across macroenvironmental, individual, and marital domains. His approach is necessarily complex as it attends to both within and between couple variations in marital behaviors and qualities nested in multiple layers of context. Paradoxically, this conceptual strength poses pragmatic challenges for researchers in that testing circular and bidirectional patterns of association require longitudinaland often dyadic — data, sophisticated analytic strategies, and adequate statistical power. Methodological advances in the past decade outlined by Acock and Washburn (Chap. 3) and others (e.g., Fincham \& Beach, 2010; Kenny et al., 2006; Kurdek, 2003; Sayer \& Klute, 2005; Whiteman \& Loken, 2006) have utility for testing more complex associations as demonstrated in some of the recent studies reviewed here. Although advanced analytic strategies for examining dyadic data and testing causal pathways make the application of the model more probable with adequate data, it is impossible for any one study or empirical test to address the multiple associations between marital behavior and the other dimensions of context outlined in the model. Instead, the model offers a guiding framework for researchers to focus on subparts of the larger causal system in a theoretically informed manner or to build a program of research that methodically examines different aspects of the model, one study at a time. Of equal import, the model crosses disciplinary boundaries and encourages scholars to be mindful of avenues of inquiry outside their academic comfort zones when approaching their own programs of research on marriage. In these ways, scholars can advance a theoretically informed and ecologically valid understanding of marriage in a manner that, at the very least acknowledges, and at best attends to the complexity inherent in Huston's model and the lived experience of married couples in the twenty-first century.

\section{Acknowledgments}

The author is grateful to Jill Walls and Yuliana Rodriguez for their assistance in the preparation of this chapter, including the initial selection and coding of studies for the content analysis and editorial assistance.

\section{References}


Adams, B. N. (2005). Theorizing the particulars of marriage. In V. L. Bengtson, A. C. Acock, K. R. Allen, P. Dilworth-Anderson, \& D. M. Klein (Eds.), Sourcebook of family theory and research (pp. 284-285). Thousand Oaks, CA: Sage.

Amato, P. R. (2004). Tension between institutional and individual views of marriage. Journal of Marriage and Family, 66, 959-965.

Amato, P. R., \& DeBoer, D. D. (2001). The transmission of marital instability across generations: Relationship skills or commitment to marriage? Journal of Marriage and Family, 63, 1038-1051.

Amato, P. R. (2007). Transformative processes in marriage: Some thoughts from a sociologist. Journal of Marriage and Family, 69, 305-309.

Amato, P. R., \& Hohmann-Marriott, B. (2007). A comparison of high- and low-distress marriages that end in divorce. Journal of Marriage and Family, 69, 621-638.

Atkins, D. C., \& Kessel, D. E. (2008). Religiousness and infidelity: Attendance, but not faith and prayer, predict marital fidelity. Journal of Marriage and Family, 70, 407-418.

Axinn, W. G., \& Thornton, A. (2000). The transformation in the meaning of marriage. In L. Waite, M. Bachrach, M. Hindin, E. Thomson, \& A. Thornton (Eds.), Ties that bind: Perspectives on marriage and cohabitation (pp. 147-165). Hawthorne, NY: Aldine de Gruyter.

Barnett, R. C., Gareis, K. C., \& Brennan, R. T. (2008). Wives'shift work schedules and husbands' and wives' well-being in dual-earner couples with children: A within-couple analysis. Journal of Family Issues, 29, 396-422.

Beach, S. R. H. (2000). Marital and family processes in depression: A scientific foundation for clinical practice. Washington, DC: APA.

Beach, S. R. H., Sandeen, E. E., \& O’Leary, K. D. (1990). Depression in marriage: A model for etiology and treatment. New York, NY: Guilford.

Beaton, J. M., Norris, J. E., \& Pratt, M. W. (2003). Unresolved issues in adult children's marital relationships involving intergenerational problems. Family Relations, 52, 143-153.

Bengtson, V. L. (2001). Beyond the nuclear family: The increasing importance of multigenerational bonds (The Burgess Award Lecture). Journal of Marriage and Family, 63, 116.

Bernard, J. (1964). The adjustment of married mates. In H. T. Christensen (Ed.), Handbook of marriage and the family (pp. 675-739). Chicago, IL: Randy McNally.

Bernard, J. (1972). The future of marriage. New York, NY: World. 
Berscheid, E. (1999). The greening of relationship science. American Psychologist, 54, 260-266.

Bose, S., \& South, S. J. (2003). Sex composition of children and marital disruption in India. Journal of Marriage and Family, 65, 996-1006.

Bowerman, C. E. (1964). Prediction studies. In H. T. Christensen (Ed.), Handbook of marriage and the family (pp. 215-246). Chicago: Randy McNally.

Bradbury, T. M. (2002). Invited program overview: Research on relationships as a prelude to action. Journal of Social and Personal Relationships, 19, 571-599.

Bradbury, T. N., Fincham, F. D., \& Beach, S. R. H. (2000). Research on the nature and determinants of marital satisfaction: A decade in review. Journal of Marriage \& the Family, 62, 964-980.

Bradbury, T. N., \& Karney, B. R. (2004). Understanding and altering the longitudinal course of marriage. Journal of Marriage and Family, 66, 862-879.

Browning, C. R. (2002). The span of collective efficacy: Extending social disorganization theory to partner violence. Journal of Marriage and the Family, 64, 833-850.

Bryant, C. M., Conger, R. D., \& Meehan, J. M. (2001). The influence of in-laws on change in marital success. Journal of Marriage \& the Family, 63, 614-626.

Bryant, C. M., \& Wickrama, K. A. S. (2005). Marital relationships of African Americans: A contextual approach. In V. McLoyd, N. Hill, \& K. A. Dodge (Eds.), Emerging issues in African American family life: Context, adaptation, and policy (pp. 111-134). New York, NY: Guilford.

Carroll, J. S., Knapp, S. J., \& Holman, T. B. (2005). Theorizing about marriage. In V. L. Bengtson, A. C. Acock, K. R. Allen, P. Dilworth-Anderson, \& D. M. Klein (Eds.), Sourcebook of family theory and research (pp. 263-288). Thousand Oaks, CA: Sage.

Cherlin, A. J. (2004). The deinstitutionalization of American marriage. Journal of Marriage and Family, 66, 848-861.

Claxton, A., \& Perry-Jenkins, M. (2008). No fun anymore: Leisure and marital quality across the transition to parenthood. Journal of Marriage and Family, 70, 28-43.

Conger, R. D., Elder, G. H., Lorenz, F. O., Conger, K., Simons, R. L., Whitbeck, L. B., Huck, S., \& Melby, J. N. (1990). Linking economic hardship to marital quality and instability. Journal of Marriage and the Family, 52, 643-656.

Conger, R. D., Rueter, M. A., \& Elder, G. H., Jr. (1999). Couple resilience to economic pressure. Journal of Personality and Social Psychology, 76, 54-71. 
Conger, R. D., Wallace, L. E., Sun, Y., Simons, R. L., McLoyd, V. C., \& Brody, G. H. (2002). Economic pressure in African American families: A replication and extension of the family stress model. Developmental Psychology, 38, 179-193.

Coontz, S. (2004). The world historical transformation of marriage. Journal of Marriage and Family, 66, 974-979.

Crawford, D. W., Houts, R. M., Huston, T. L., \& George, L. J. (2002). Compatibility, leisure, and satisfaction in marital relationships. Journal of Marriage and Family, 64, 433-449.

Crespo, C., Davide, I. N., Costa, M. E., \& Fletcher, G. J. O. (2008). Family rituals in married couples: Links with attachment, relationship quality, and closeness. Personal Relationships, 15, 191-203.

Crouter, A. C., \& Booth, A. (2003). Children's influence on family dynamics: The neglected side of family relationships. Mahwah, NJ: Erlbaum.

Crouter, A. C., \& Booth, A. (2004). Work-family challenges for low-income parents and their children. Mahwah, NJ: Erlbaum.

Crouter, A. C., \& Helms-Erikson, H. M. (2000). Work and family from a dyadic perspective: Variations in inequality. In R. Milardo \& S. Duck (Eds.), Families as relationships (pp. 99-115). New York, NY: Wiley.

Cullen, J. C., Hammer, L. B., Neal, M. B., \& Sinclair, R. R. (2009). Development of a typology of dual-earner couples caring for children and aging parents. Journal of Family Issues, 30, 458483.

Curran, M., Hazen, N., Jacobvitz, D., \& Sasaki, T. (2006). How representations of the parental marriage predict marital emotional attunement during the transition to parenthood. Journal of Family Psychology, 20, 477-484.

Curtis, K. T., \& Ellison, C. G. (2002). Religious heterogamy and marital conflict. Journal of Family Issues, 23, 551-576.

Cutrona, C. E., Russell, D. W., Abraham, W. T., Gardner, K. A., Melby, J. M., Bryant, C., \& Conger, R. D. (2003). Neighborhood context and financial strain as predictors of marital interaction and marital quality in African American couples. Personal Relationships, 10, 389 409.

Cutrona, C. E., Shaffer, P. A., Wesner, K. A., \& Gardner, K. A. (2007). Optimally matching support and perceived spousal sensitivity. Journal of Family Psychology, 21, 754-758.

Davey, A., \& Szinovacz, M. E. (2004). Dimensions of marital quality and retirement. Journal of Family Issues, 25, 431-464. 
DeLongis, A., Capreol, M., Holtzman, S., O’Brien, T., \& Campbell, J. (2004). Social support and social strain among husbands and wives: A multilevel analysis. Journal of Family Psychology, 18, 470-479.

DeMaris, A. (2007). The role of relationship inequity in marital disruption. Journal of Social and Personal Relationships, 24, 177-195.

Dush, C. M., Cohan, C. L., \& Amato, P. R. (2003). The relationship between cohabitation and marital quality and stability: Change across cohorts? Journal of Marriage and Family, 65, 539549.

England, P., \& Edin, K. (2007). Unmarried couples with children. New York, NY: Russell Sage.

Erickson, R. J. (1993). Reconceptualizing family work: The effect of emotion work on perceptions of marital quality. Journal of Marriage and the Family, 55, 888-900.

Fincham, F. D., \& Beach, S. R. H. (2010). Marriage in the new millennium. Journal of Marriage and Family, 72(3), 630-649.

Fincham, F. D., Beach, S. T., \& Davila, J. (2007). Longitudinal relations between forgiveness and conflict resolution in marriage. Journal of Family Psychology, 21, 542-545.

Fincham, F. D., \& Bradbury, T. N. (1987). The assessment of marital quality: A reevaluation. Journal of Marriage \& the Family, 49, 797-809.

Fincham, F. D., Harold, G. T., \& Gano-Phillips, S. (2000). The longitudinal association between attributions and marital satisfaction: Direction of effects and role of efficacy expectations. Journal of Family Psychology, 14, 267-285.

Fincham, F. D., \& Linfield, K. J. (1997). A new look at marital quality: Can spouses feel positive and negative about their marriage? Journal of Family Psychology, 11, 489-502.

Fincham, F. D., Paleari, F. G., \& Regalia, C. (2002). Forgiveness in marriage: The role of relationship quality, attributions, and empathy. Personal Relationships, 9, 27-37.

Fincham, F. D., Stanley, S. M., \& Beach, S. R. (2007). Transformative processes in marriage: An analysis of emerging trends. Journal of Marriage and Family, 69, 275-292.

Fingerman, K. L., \& Hay, E. L. (2002). Searching under the streetlight?: Age biases in the personal and family relationships literature. Personal Relationships, 9, 415-433.

Frye, N. E., \& Karney, B. R. (2006). The context of aggressive behavior in marriage: A longitudinal study of newlyweds. Journal of Family Psychology, 20, 12-20. 
Gordon, K. C., Hughes, F. M., Tomcik, N. D., Dixon, L. J., \& Litzinger, S. C. (2009). Widening spheres of impact: The role of forgiveness in marital and family functioning. Journal of Family Psychology, 23, 1-13.

Gottman, J. M. (1993). A theory of marital dissolution and stability. Journal of Family Psychology, 7, 57-75.

Helms, H. M., Crouter, A. C., \& McHale, S. M. (2003). Marital quality and spouses' marriage work with close friends and each other. Journal of Marriage and Family, 65, 963-977.

Helms, H. M., Proulx, C. M., Klute, M. M., McHale, S. M., \& Crouter, A. C. (2006). Patterns of spouses' gender-typed attributes and their links with marital quality: A pattern analytic approach. Journal of Social and Personal Relationships, 23, 843-864.

Helms, H. M., Supple, A. J., \& Proulx, C. M. (2011). Mexican origin couples in the early years of parenthood: Marital well-being in ecological context. Journal of Family Theory and Review, 3(2), 67-95.

Helms, H. M., Walls, J. K., Crouter, A. C., \& McHale, S. M. (2010). Provider role attitudes, marital satisfaction, role overload, and housework: A dyadic approach. Journal of Family Psychology, 24(5), 568-577.

Helms, H. M., Walls, J. K., \& Demo, D. H. (2010). Everyday hassles and family stress. In S. J. Price \& C. Price (Eds.), Families and change: Coping with stressful events (4th ed., pp. 357380). Thousand Oaks, CA: Sage.

Hetherington, E. M. (2003). Intimate pathways: Changing patterns in close personal relationships across time. Family Relations, 52, 318-331.

Howe, G. W., Levy, M. L., \& Caplan, R. D. (2004). Job loss and depressive symptoms in couples: Common stressors, stress transmission, or relationship disruption? Journal of Family Psychology, 18, 639-650.

Huston, T. L. (2000). The social ecology of marriage and other intimate unions. Journal of Marriage and Family, 62, 298-320.

Huston, T. D., \& Melz, H. (2004). The case for (promoting) marriage: The devil is in the details. Journal of Marriage and Family, 66, 943-958.

Johnson, M. P., Caughlin, J. P., \& Huston, T. L. (1999). The tripartite nature of marital commitment: Personal, moral, and structural reasons to stay married. Journal of Marriage and the Family, 61, 160-177.

Kan, M. L., McHale, S. M., \& Crouter, A. C. (2008). Interparental incongruence in differential treatment of adolescent siblings: Links with marital quality. Journal of Marriage and Family, 70, $466-479$. 
Karney, B. R. (2007). Not shifting but broadening marital research: Comments on Fincham, Stanley, and Beach. Journal of Marriage and Family, 69, 310-314.

Karney, B. R., \& Bradbury, T. N. (1995). The longitudinal course of marital quality and stability: A review of theory, method, and research. Psychological Bulletin, 118, 3-34.

Karney, B. R., \& Bradbury, T. N. (2000). Attributions in marriage: State or trait? A growth curve analysis. Journal of Personality and Social Psychology, 78, 295-309.

Karney, B. R., \& Bradbury, T. N. (2005). Contextual influences on marriage: Implications for policy and intervention. Current Directions in Psychological Science, 14, 171-174.

Karney, B. R., \& Crown, J. S. (2007). Families under stress: An assessment of data, theory, and research on marriage and divorce in the military (MG-599-OSD). Santa Monica, CA: RAND.

Kearns, J. N., \& Leonard, K. E. (2004). Social networks, structural interdependence, and marital quality over the transition to marriage: A prospective analysis. Journal of Family Psychology, $18,383-395$.

Kelley, H. H., Berscheid, E., Christensen, A., Harvey, J. H., Huston, T. L., Levinger, G., \& Peterson, D. R. (1983). Close relationships. New York, NY: Freeman.

Kelly, S., \& Floyd, F. J. (2006). Impact of racial perspectives and contextual variables on marital trust and adjustment for African American couples. Journal of Family Psychology, 20, 79-87.

Klute, M. M., Crouter, A. C., Sayer, A. G., \& McHale, S. M. (2002). Occupational self-direction, values, and egalitarian relationships: A study of dual-earner families. Journal of Marriage and Family, 64, 139-151.

Kenny, D. A., Kashy, D. A., \& Cook, W. L. (2006). The analysis of dyadic data. New York, NY: Guilford.

Kurdek, L. A. (2002). Predicting the timing of separation and marital satisfaction: An eight-year prospective longitudinal study. Journal of Marriage and Family, 64, 163-179.

Kurdek, L. A. (2003). Methodological issues in growth-curve analyses with married couples. Personal Relationships, 10, 235-266.

Laurenceau, J., Barrett, L. F., \& Rovine, M. J. (2005). The interpersonal process model of intimacy in marriage: A daily-diary and multilevel modeling approach. Journal of Family Psychology, 19, 314-323.

Lawrence, E., \& Bradbury, K. (2007). Trajectories of change in physical aggression and marital satisfaction. Journal of Family Psychology, 21, 236-247. 
Leidy, M. S., Parke, R. D., Cladis, M., Coltrane, S., \& Duffy, S. (2009). Positive marital quality, acculturative stress, and child outcomes among Mexican Americans. Journal of Marriage and Family, 71, 833-847.

Mattson, R. E., Paldino, M., \& Johnson, M. D. (2007). The increased construct validity and clinical utility of assessing relationship quality using separate positive and negative dimensions. Psychological Assessment, 19, 146-151.

McAdoo, H., Martinez, E., \& Hughes, H. (2005). Ecological changes in ethnic families of color. In V. Bengtson, A. Acock, K. Allen, P. Dilworth-Anderson, \& D. Klein (Eds.), Sourcebook of family theory and research: An interactive approach (pp. 191-212). Thousand Oaks, CA: Sage.

McKee-Ryan, F. M., Song, Z., Wanberg, C. R., \& Kinicki, A. J. (2005). Psychological and physical well-being during unemployment: A meta-analytic study. Journal of Applied Psychology, 90, 53-76.

Meijer, A. M., \& van den Wittenboer, G. L. H. (2007). Contribution of infants' sleep and crying to marital relationship of first-time parent couples in the 1st year after childbirth. Journal of Family Psychology, 21, 49-57.

Milardo, R. M., \& Helms-Erikson, H. (2000). Network overlap and third-party influences in close relationships. In C. Hendrick \& S. Hendrick (Eds.), Close relationships: A sourcebook (pp. 33-45). Thousand Oaks, CA: Sage.

Murry, V. M., Brown, P. A., Brody, G. H., Cutrona, C. E., \& Simons, R. L. (2001). Racial discrimination as a moderator of the links among stress, maternal psychological functioning, and family relationships. Journal of Marriage and Family, 63, 915-926.

Murry, V. M., Harrell, A. W., Brody, G. H., Chen, Y., Simons, R. L., Black, A. R., et al. (2008). Long term effects of stressors on relationship well-being and parenting among rural African American women. Family Relations., 57, 117-127.

Neff, L. A., \& Karney, B. R. (2007). Stress crossover in newlywed marriage: A longitudinal and dyadic perspective. Journal of Marriage and Family, 69, 594-607.

O’Leary, S. G., \& Slep, A. M. (2006). Precipitants of partner aggression. Journal of Family Psychology, 20, 344-347.

Osborne, C., Manning, W. D., \& Smock, P. J. (2007). Married and cohabiting parents' relationship stability: A focus on race and ethnicity. Journal of Marriage and Family, 69, 13451366.

Pasley, K., Kerpelman, J., \& Guilbert, D. E. (2001). Gendered conflict, identity disruption, and marital instability: Expanding Gottman's model. Journal of Social and Personal Relationships, $18,5-27$. 
Perry-Jenkins, M., Repetti, R. L., \& Crouter, A. C. (2000). Work and family in the 1990s. Journal of Marriage and the Family, 62, 981-998.

Peters, M. F., \& Massey, G. C. (1983). Mundane extreme environmental stress in family stress theories: The case of Black families in White America. Marriage and Family Review, 6, 193218.

Presser, H. B. (2000). Nonstandard work schedules and marital instability. Journal of Marriage and Family, 62, 93-110.

Previti, D., \& Amato, P. R. (2004). Is infidelity a cause or a consequence of poor marital quality? Journal of Social and Personal Relationships, 21, 217-230.

Proulx, C. M., Helms, H. M., \& Buehler, C. (2007). Marital quality and personal well-being: A meta-analysis. Journal of Marriage and Family, 69, 576-593.

Proulx, C. M., Helms, H. M., \& Payne, C. C. (2004). Wives' domain specific “marriage work" with spouse and friend: Links to marital quality. Family Relations, 53, 393-404.

Robles, T. F., \& Kiecolt-Glaser, J. K. (2003). The physiology of marriage: Pathways to health. Physiology and Behavior, 79, 409-416.

Sayer, A. G., \& Klute, M. M. (2005). Analyzing couples and families. In V. L. Bengtson, A. Acock, K. R. Allen, P. Dilworth-Anderson, \& D. M. Klein (Eds.), Sourcebook of family theory and research (pp. 289-313). Thousand Oaks, CA: Sage.

Schoebi, D. (2008). The coregulation of daily affect in marital relationships. Journal of Family Psychology, 22, 595-604.

Serewicz, M. C. M., \& Canary, D. J. (2008). Assessments of disclosure from the in-laws: Links among disclosure topics, family privacy orientations, and relational quality. Journal of Social and Personal Relationships, 25, 333-357.

Simons, R. L., Whitebeck, L. B., Melby, J. N., \& Wu, C. I. (1994). Economic pressure and harsh parenting. In R. D. Conger \& G. H. Elder (Eds.), Families in troubled times: Adapting to change in rural America (pp. 207-222). New York, NY: Gruyter.

Spotts, E. L., Prescott, C., \& Kendler, K. (2006). Examining the origins of gender differences in marital quality: A behavior genetic analysis. Journal of Family Psychology, 20, 605-613.

Sroufe, L. A., Egeland, B., Carlson, E., \& Collins, W. A. (2005). The development of the person: The Minnesota study of risk and adaptation from birth to adulthood. New York, NY: Guilford.

Stanley, S. M., Rhoades, G. K., \& Markman, H. J. (2006). Sliding versus deciding: Inertia and the premarital cohabitation effect. Family Relations, 55, 499-509. 
Stets, J. E. (1993). Control in dating relationships. Journal of Marriage and Family, 55, 673685.

Stets, J. E. (1995). Modeling control in relationships. Journal of Marriage and Family, 57, 489501.

Stets, J. E., \& Hammons, S. A. (2002). Gender, control, and marital commitment. Journal of Family Issues, 23, 3-25.

Tach, L., \& Halpern-Meekin, S. (2009). How does premarital cohabitation affect trajectories of marital quality? Journal of Marriage and Family, 71, 298-317.

Trent, K., \& South, S. J. (2003). Spousal alternatives and marital relations. Journal of Family Issues, 24, 787-810.

Tucker, M. B., \& Crouter, A. C. (2008). Enduring couples in varying sociocultural contexts. Family Relations, 57(2), 113-116.

Umberson, D., Williams, K., Powers, D. A., Liu, H., \& Needham, B. (2005). Stress in childhood and adulthood: Effects on marital quality over time. Journal of Marriage and Family, 67, 13321347.

Updegraff, K. A., Crouter, A. C., Umaña-Taylor, A., \& Cansler, E. (2007). Work-family linkages in the lives of families of Mexican origin. In J. Lansford, K. Deater-Deckard, \& M. Bornstein (Eds.), Immigrant families in contemporary society (pp. 250-267). New York, NY: Guilford.

Voydanoff, P. (2005). Social integration, work-family conflict and facilitation, and job and marital quality. Journal of Marriage and Family, 67, 666-679.

Walker, A. (2004). A symposium on marriage and its future. Journal of Marriage and Family, $66,843-847$.

Whisman, M. A., Gordon, K. C., \& Chatav, Y. (2007). Predicting sexual infidelity in a population-based sample of married individuals. Journal of Family Psychology, 21, 320-324.

Whiteman, S. D., \& Loken, E. (2006). Comparing analytic techniques to classify dyadic relationships: An example using siblings. Journal of Marriage and Family, 68, 1370-1382.

Wickrama, K. A. S., Bryant, C. M., \& Wickrama, T. K. A. (2010). Perceived community disorder, hostile marital interactions, and self-reported health of African American couples: An interdyadic process. Personal Relationships, 17, 525-531.

World Bank. (2005, November). Migration can deliver welfare gains, reduce poverty, says global economic prospects 2006. Retrieved March 19, 2008, 
from http://web.worldbank.org/WBSITE/EXTERNAL/NEWS/0,,contentMDK:20724214 pageP $\underline{\text { K:64257043 piPK:437376 theSitePK:4607,00.html. }}$

Yeong, C. L. (2008, March 13). Pilgrim's Pride to close N. C. facility. Charlotte Observer. Retrieved March 25, 2008 from http://www.charlotte.com/business/story/534230.html.

Zhang, Y., \& Van Hook, J. (2009). Marital dissolution among interracial couples. Journal of Marriage and Family, 71, 95-107. 